\title{
Miedo y sentido de pertenencia del territorio del estado-nación colombiano
}

\section{Fear and sense of belonging of the Colombian state-nation territory}

\section{Carlos Eduardo Rojas Rojas (D)}

Universidad de Caldas

carlos.rojas_ro@ucaldas.edu.co

\begin{abstract}
Resumen
Este escrito se ocupa del miedo y el sentido de pertenencia del territorio del Estado-nación colombiano y es uno de los productos de una investigación ${ }^{1}$ que se realizó con base en el modelo conceptual nombrado Emoterras, cuyos rasgos generales se presentan en la introducción. Inicialmente, se exponen los hallazgos a partir de una de las objetivaciones del miedo: el Palacio de Justicia localizado en la Plaza de Bolívar de Bogotá. Luego se abordan el gobierno desde el miedo a la democracia y al pueblo; y los miedos de los sectores subalternos y la defensa de sus derechos. Adicionalmente, se presenta un apartado titulado del miedo al terror: violencia politica y acciones de las víctimas, y se finaliza con el paso del miedo a la subjetivación de la esperanza; para concluir que el miedo ha obstaculizado la formación del sentimiento de pertenencia de los territorios del Estado-nación colombiano.
\end{abstract}

Palabras Clave: Emoterras, objetivación del miedo, institucionalización del miedo, terror, víctimas, Colombia

\begin{abstract}
This paper deals with the fear and sense of belonging of the Colombian nation-state territory, this is one of the products of a wider investigation that was carried out based on the conceptual model named Emoterras whose general features are presented in the introduction. Initially, presents the findings from one of the objectifications of fear, the Palace of Justice located in the Plaza de Bolivar of Bogotá, then treated the government from the democracy and the people fear, and the fears of the subaltern sectors and the defense of their rights; In adition, presents a section entitled fear of terror: political violence and actions of the victims; and ends the passage of fear to the subjectification of hope. Concluding that fear has hampered the formation of the feeling of belonging of the territories of the Colombian nation-state.
\end{abstract}

Key Words: Emoterras, objectification of fear, institutionalization of fear, terror, victims, Colombia

Articulo: Recibido el 26 de febrero de 2018 y aprobado 19 de febrero de 2019.

\section{Cómo citar este articulo}

Rojas Rojas, CE. (2019). Miedo y sentido de pertenencia del territorio del estado-nación colombiano. Reflexión Politica 21 (41), pp. 191-205, DOI: https://doi.org/10.29375/01240781.3251

1 Se trata de la tesis titulada Emoterras del Estado-nación colombiano realizada en el Doctorado en Estudios Territoriales de la Universidad de Caldas, misma que fue distinguida como Meritoria. 


\section{Introducción}

El miedo es una de las emociones relacionadas con el sentimiento de extrañamiento de los territorios del Estado-nación colombiano. Este es uno de los hallazgos de una investigación que se fijó como objetivo determinar las emociones vinculadas con el sentimiento de pertenencia o de extrañamiento de dicho territorio ${ }^{2}$; para ello se concibió un modelo conceptual denominado Emoterras, mediante el cual es posible comprender las relaciones entre emociones y territorio, y aplicarlo a distintas escalas, momentos históricos y actores sociales.

Como puede apreciarse en la Figura 1, el modelo lo conforman cuatro conceptos: emociones, territorio, actores y tiempo, así como las relaciones entre ellos: objetivación (emociones emplazadas en un territorio), subjetivación (emociones que suscita un territorio), producción del territorio y de los actores sociales, experimentación y provocación de emociones por parte de distintos actores sociales.

\section{EMOTERRAS}

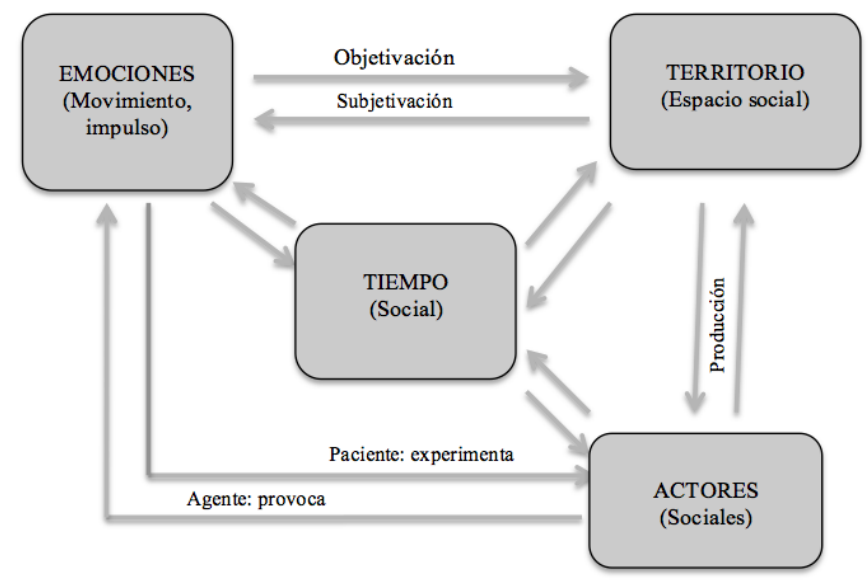

Figura 1. Modelo EMOTERRAS. Elaboración propia.

Las emociones se entienden como una forma de la experiencia en que las percepciones del mundo circundante (objeto), o su evocación en la memoria, impulsan al movimiento. Les atribuimos cierta razonabilidad, involucran creencias y pensamientos evaluativos con respecto al objeto, pueden producirse mediante el discurso; las emociones mismas pueden evaluarse y, también, educarse (Nussbaum, 2006).

El miedo, en particular, surge ante un peligro que se advierte como inminente (Aristóteles, 2013), se objetiva en un territorio por medio de construcciones u otras clases de emplazamientos con las cuales un determinado actor, en calidad de paciente, busca protegerse, mientras que, en calidad de agente, puede provocar el miedo en otros recurriendo a intrusiones en sus respectivos territorios que, por lo general, son violentas y desembocan en el terror.

Por territorio se comprende la objetivación de la acción social humana en la superficie terrestre. Las relaciones políticas, económicas, sociales o culturales entre los integrantes de un grupo humano determinado, toman cuerpo en los territorios y comprenden aspectos tales como la apropiación, los límites, la defensa, los conflictos, las concepciones, las clasificaciones, las escalas, los sentidos, las funciones (Monet, 2013; Zambrano, 2013).

El territorio del Estado-nación es el espacio geográfico gobernado por el complejo institucional (ejecutivo, legislativo, judicial) que ejerce el monopolio legítimo de la fuerza, la justicia y la tributación

$2 \quad$ Mientras que al producir un territorio los actores sienten que éste les pertenece o que son parte de él, el sentimiento de extrañamiento hace referencia a lo opuesto: el territorio que han producido les resulta extraño, no es de ellos ni se sienten parte de él. 
para mantener un orden determinado entre grupos sociales que permanecen en conflicto para consagrar y ejercer sus derechos. El territorio del Estado no siempre se corresponde con el de la nación (Weber, 1997; Habermas, 1998).

Los actores son sujetos capaces de lenguaje y acción (Habermas, 1999), producen territorios y experimentan emociones tanto como son producto territorial y emocional. En el caso de las emoterras relacionadas con el sentimiento de pertenencia del territorio del Estado-nación, los actores pertinentes son: los ciudadanos, los nacionales, las comunidades, las organizaciones sociales y los partidos políticos.

Las emociones, los territorios y los actores tienen cada uno su temporalidad y convergen en un momento histórico determinado; también se encuentran variadas concepciones y experiencias del tiempo y es posible determinar distintas vivencias con respecto a su duración, intensidad, frecuencia o ritmo. Para entender el papel de la memoria y de la incertidumbre con respecto al porvenir en la producción de las emociones y los territorios, resulta fructífera la comprensión del tiempo como interpenetración de pasado y futuro en el presente (Cassirer, 1968).

Para el estudio del miedo en la escala nacional se consideraron varios lugares y objetivaciones (edificaciones, placas, monumentos e instalaciones); finalmente se seleccionó el Palacio de Justicia, localizado en la Plaza de Bolivar de Bogotá, dada la riqueza de elementos que remiten a acontecimientos significativos para distintos grupos humanos en el proceso de construcción del Estado-nación colombiano, desde el momento de su declaratoria como Estado independiente en 1810. Estos elementos muestran algunas continuidades con el régimen colonial y no están relegados al pasado sino que están vivos en la memoria, marcan las decisiones y acciones futuras, y son susceptibles de una comprensión de carácter histórico hermenéutico.

Dada la conflictividad entre los distintos actores sociales, se buscó precisar el miedo de los sectores dominantes y de los subordinados (en tanto pacientes), así como las formas en que los primeros (en tanto agentes) han gobernado el territorio haciendo uso de la emoción en cuestión, y las formas en que los segundos han enfrentado el miedo, se han organizado y continúan buscando las formas de ejercer sus derechos.
Seacudióa fuentes primariasy secundarias, se realizaron visitas a los lugares objeto de estudio en las que se recogieron testimonios de diferentes tipos de usuarios (guías turísticos, comerciantes, turistas, transeúntes), se recopilaron narraciones sobre los sucesos acaecidos en cada uno de los lugares, se organizó un archivo fotográfico del cual se seleccionaron algunas imágenes que permitían apreciar los fenómenos de objetivación y subjetivación de la emoción estudiada; se decidió partir de la objetivación más reciente para luego irse sumergiendo en las más antiguas.

\section{Objetivación del miedo}

En el costado norte de la plaza de Bolivar está el Palacio de Justicia, es el tercer edificio destinado para servir de sede a las altas cortes, fue puesto en servicio en el año 2000 luego de siete años de construcción y del silencioso desmonte pieza por pieza de su antecesor.

El segundo edificio se había comenzado a construir en 1960 y se puso en servicio sin que se hubiera finalizado la obra. En su interior se desarrollaron los luctuosos acontecimientos del 6 y 7 de noviembre de 1985: la toma armada por el grupo guerrillero $\mathrm{M}-19$, la retoma de las fuerzas armadas, el asesinato de 98 personas, 11 de ellas magistrados, la desaparición de otras 11 personas y el incendio (Figura 2) con todo y ocupantes (secuestradores y rehenes); hechos todos que han buscado sumergirse en el olvido.

El primer edificio fue construido en el costado occidental de la Plaza (sobre la carrera octava), funcionó de 1920 a 1949 cuando fue incendiado luego del asesinato del dirigente liberal Jorge Eliécer Gaitán a pocas cuadras de la plaza.

Estos antecedentes violentos marcaron el diseño del actual Palacio de Justicia en términos de miedo y olvido como lo ilustra la arquitecta e historiadora Tania Maya Sierra. Entre los mecanismos de defensa ante el peligro están: evadir los sucesos o condiciones atemorizantes, callar, olvidar o no querer recordar, mantenerse alerta, buscar protección y protegerse. Estos mecanismos se activan cuando la sospecha del peligro inminente puede ser confirmada y se refuerza con los hechos del pasado:

A partir de dicha recurrencia, el miedo se instala y en consecuencia se busca que la protección sea permanente. Entre las estrategias de protección 


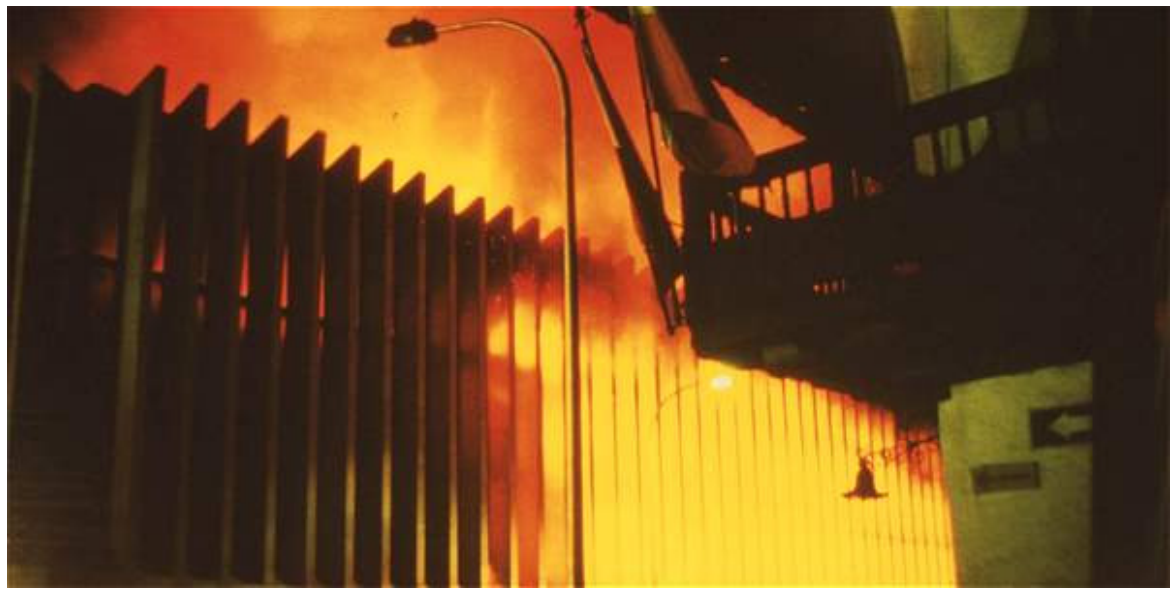

Figura 2. Incendio del Palacio de Justicia visto desde la Casa del Florero. Bogotá, 6 de noviembre de 1985. Periódico El Tiempo, 2015.

prima la de no demostrar el miedo; por lo tanto, es necesario ocultarlo, una de las formas para lograr este objetivo es camuflarlo (Maya, 2007, p. 24).

El camuflaje o enmascaramiento del miedo en el actual Palacio de Justicia se expresa, según Maya, en un aparente carácter abierto del edificio, conforme con su función de edificio público, pero que sólo se puede apreciar en el acceso mismo al palacio y no desde la Plaza de Bolívar, de la cual está separado por un muro con el cual se intentó salvar el desnivel existente entre las carreras séptima y octava. Otras formas de enmascaramiento son el fallido intento de imitación del Capitolio Nacional o el esfuerzo por borrar cualquier reminiscencia del edificio anterior.

A juicio de Tania Maya, la seguridad, como respuesta al miedo, no sólo fue el objetivo primordial sino que desplazó la expresión arquitectónica del palacio como símbolo del poder judicial, que tampoco cumple con su carácter de edificio público. La prioridad a los accesos, los sistemas de circulación, los tipos de recorridos internos, la ubicación y número de los puntos fijos llevaron a una construcción laberíntica; se diferenciaron los accesos y circulación de magistrados y del público; se contemplaron las tácticas de evacuación tales como desalojo de ascensores, oficinas, los restantes espacios y del edificio; los sistemas constructivos, la tecnología, el tipo y la calidad de los materiales, los mecanismos para el control de los accesos, uso de equipos y demás dispositivos de seguridad como alarmas, cámaras, sensores, son todo un conjunto de medios que garantizan la protección.
Para Maya, al nuevo Palacio pudo dársele un carácter conmemorativo como lo sugirió Carlos Medellín, hijo de uno de los magistrados inmolados:

Al fin y al cabo, los magistrados, magistrados auxiliares y trabajadores asesinados, jamás abandonaron el Palacio. Los funerales de entonces fueron algo más simbólico que real. La mayor parte de los cadáveres desaparecieron con el fuego. Muchos de los cuerpos no fueron encontrados. Las cenizas fueron colocadas en los ataúdes (Maya, 2007, p. 22).

\section{El gobierno desde el miedo a la democracia y al pueblo}

En la fachada de este tercer edificio, al igual que en el anterior, están esculpidas estas palabras de Francisco de Paula Santander: "Colombianos: las armas os han dado la independencia, las leyes os darán la libertad" que, contrastadas con los hechos que allí se han desarrollado, traen a la memoria las palabras del constitucionalista Hernando Valencia Villa: "En este sentido puede afirmarse que el Estado colombiano tiene una estructura bolivariana y un estilo santanderista, es decir, un marco autoritario y un carácter legalista o un esquema rusoniano y jacobino y una manera benthamista" (Valencia, 2010, p. 117).

Para Valencia, el miedo a la anarquía, el excesivo celo puesto en mantener el orden social, es uno de los factores que explican que los colombianos nos hayamos mantenido precisamente en lo contrario: la violencia en medio de una democracia restringida. 
La participación política que se aparte del orden y disciplinamiento ha sido considerada por las clases dominantes como una, en palabras de Santander, desastrosa anarquía frente a la cual han recurrido a distintas medidas para frenar la libertad de los súbditos: el voto censatario y la negación del mismo a las mujeres, las permanentes reformas legales que se presentan como solución a los problemas pero que luego se incumplen al no ponerlas en práctica, el uso reiterado (permanente) de los recursos de excepción tales como el estado de sitio de la Constitución de 1886, entre otros.

Valencia llega a estas conclusiones luego de adentrarse en el estudio de las 16 constituciones nacionales expedidas entre 1811 y 1991, con las 89 reformas introducidas hasta 1997, para mostrar las distintas correlaciones entre dominación y hegemonía en la construcción del Estado-nación en Colombia.

Estos conceptos los toma de Antonio Gramsci quien:

Distinguía dos funciones principales en el Estado: la dominación, que es el control físico, corporal de la población dentro del territorio, usualmente por medios militares y policivos; y la hegemonía, que es el control intelectual y moral del pueblo de una nación a través de la ideología constitucional y legal (Valencia, 2010, p. 82).

Valencia y Liliana Estupiñán (2001) comparten el argumento según el cual primero construimos Estado y luego nación, Valencia se lo adjudica a Simón Bolívar:

El caudillo venezolano fue el primero y el mejor entre los padres fundadores en darse cuenta de que el problema principal que encaraban era que no había una nación con base en la cual pudiera construirse un Estado y menos aún constituirse y gobernarse una república. La tarea por hacer, por consiguiente, era doble: primero, construir el Estado antes que la nación, y segundo, extraer la nación del Estado (Valencia, 2010, pp. 95-96).

Valencia juzga que en los territorios liberados del dominio español no existían naciones modernas dado que se trataba de sociedades altamente heterogéneas y jerarquizadas, por lo cual las formas de la democracia constitucional importadas de Europa y Norteamérica fueron consideradas por los líderes independentistas como garantía de unidad nacional, orden político y estabilidad legal; elementos estos que permitirian producir la integración cultural y económica tanto de la población como de su territorio y, luego sí, conformar un régimen republicano.

Según Valencia, los estados nacionales modernos en Europa son comunidades de origen que gradualmente modificaron su economía y su cultura para, gracias al ingenio de la burguesía, transformar el criterio de legitimación del poder público y crear el Estado moderno en unos territorios determinados. En nuestro caso, en América, las naciones vienen dadas como comunidades de destino, grupos humanos que primero cambiaron la forma de legitimación del poder público, crearon Estado, y luego buscaron transformar su economía y su cultura en unos territorios determinados. En otros términos, allá en el territorio de la nación se crea el territorio del Estado, mientras que aquí en el territorio del Estado creamos el territorio de la nación.

Para el jurista, nuestras sociedades altamente heterogéneas y jerarquizadas son la expresión de la ausencia de nación. Encuentra grupos humanos que han roto las cadenas de la esclavitud y con ellas todas las instituciones coloniales, que tienen ante sí la tarea de formar nuevas instituciones y las personas que las pongan a funcionar, a partir de elementos raciales heterogéneos, requieren construir una cultura común y apropiarse de una extensa, fértil y agreste geografía.

Sintetiza con estas palabras del intelectual José María Samper, político y cofundador de la Universidad Nacional de Colombia en el siglo XIX:

Una sociedad compuesta de muy heterogéneos elementos (un reducido número de españoles peninsulares, otro mayor de españoles criollos, y otro muy considerable de indios abyectos, negros esclavos y mestizos diversos); sociedad compuesta de poco más de un millón de almas, difundida en un territorio de 140 millones de hectáreas, sin vías de comunicación, ni industria, ni comercio, ignorante en extremo, y que súbitamente salía del limbo del régimen colonial para pasar al cielo de la independencia republicana (Valencia, 2010, p. 87).

Darle forma al Estado para construir nación implica: transformar la esclavitud y el servilismo en ciudadanía, superar las diferencias raciales en cultura común; la ignorancia en educación; la geografía fragmentada, indómita e incomunicada en territorios apropiados y comunicados por medio 
de actividades productivas $\mathrm{y}$, de esta manera, constituir la res publica, el bien común.

Al igual que Estupiñán, Valencia considera que esta es una tarea aún por realizar: el Estado se ha convertido en el instrumento de dominación de pequeños grupos $u$ oligarquías que no han podido o no han querido administrar personas y territorios haciendo uso del otro recurso del que disponen: la hegemonía.

Este predominio del recurso de la dominación sobre la hegemonía podría explicarse por el miedo a la democracia, que para Valencia constituye el ethos de la clase dirigente colombiana a lo largo de la historia y que resulta ser complementaria del desprecio expresado en las ya citadas palabras de José María Samper.

Francisco de Paula Santander, quien se formó bajo la influencia del utilitarismo de Bentham, en 1821 manifestaba:

Me gusta mucho la opinión de usted de que si dejamos a los pueblos en absoluta libertad, volveremos a la antigua desastrosa anarquía, y que es preciso hacerlos libres contra su voluntad; tal ha sido el principio que me ha dirigido para frenar un poco la libertad de los súbditos [...] y enseñar al pueblo a obedecer ciegamente, y que después es entrar en adoptar todas las instituciones liberales de un pueblo verdaderamente libre (Valencia, 2010, p. 123).

Con matices y variaciones, este miedo ha sido común a los distintos sectores dominantes que, habiendo adoptado todos la ideología liberal, se distinguen entre republicanos e individualistas: los primeros más afines a la doctrina francesa, afincan la soberanía en la nación y se inclinan hacia los modelos representativos de la democracia y de organización centralista del estado; los segundos, con sus simpatías puestas en los nacientes Estados Unidos se declaran individualistas, partidarios de modelos democráticos participativos y de una organización federativa o regionalista del Estado.

El miedo también se deriva de las distintas lecturas de situaciones concretas. Antonio Nariño, quien promovía la independencia total de España, propugnaba por el centralismo como forma eficiente de administrar los exiguos recursos de las nacientes repúblicas y para enfrentar el peligro de la reconquista española. Por su parte, Camilo Torres Tenorio, quien inicialmente era partidario de una mayor participación dentro del régimen monárquico, desestimaba la reacción violenta del monarca español y se unió a los sectores federalistas.

Estas diferencias doctrinarias que tendrían luego a Bolivar y a Santander como máximos exponentes, darían paso a la formación de los partidos liberal y conservador, para los que sus diferencias pasan a segundo plano cuando sienten amenazadas sus posiciones de dominio y cuando consideran que la participación de sectores subalternos pone en peligro el orden tan difícilmente construido.

Fernán González coincide en que la Independencia americana planteó el reto de inventar y construir el sentimiento nacionalista pero, agrega, tenía el obstáculo del llamado miedo al pueblo:

Otro de los rasgos de la América hispana fue la multiplicidad de caminos de independencia, pues en muchas de las futuras naciones el temor a la insurgencia de las clases populares, ejemplificada en las revoluciones de Francia y Haití, llevaba a las élites criollas a desconfiar de la independencia (2016, p. 111).

Para González, el miedo al pueblo tenía antecedentes en la colonia. Entre las élites criollas había quienes se oponían a la Independencia pues encontraban que, como en Francia, el terror era uno de los recursos para imponer la revolución: "La dictadura del Terror y la feroz represión de movimientos contrarrevolucionarios, como el de la Vendée, atestiguan el rechazo que encontraban los esfuerzos de los revolucionarios por instituir formas de gobierno directas y centralizadas" (González, 2016, p. 118).

El historiador sostiene que es necesario realizar un análisis multiescalar y diferenciado en el tiempo y el espacio, conclusión a la que llega luego de encontrar las limitaciones de la hipótesis inicial sobre la pérdida del monopolio de la fuerza y de la justicia, según la cual, en las áreas centrales y de más antiguo poblamiento se presentaban bajos índices de violencia $\mathrm{y}$ altos niveles de institucionalidad estatal; mientras que en las zonas periféricas y de poblamiento más reciente (colonización campesina espontánea y barrios marginales de las ciudades), se encontraban altos índices de violencia y bajos niveles de institucionalización estatal. Propone entonces el concepto de presencia diferenciada del Estado que:

Se concreta en diversos grados de estatización e institucionalización nacional de la vida política, a los cuales corresponden variados tipos de 
relaciones entre el Estado central y los poderes locales y regionales. Tal diversidad se refleja asimismo en maneras diferenciadas de ejercicio de la ciudadanía y en diversos estilos de cultura política, que rompen con la concepción abstracta y homogeneizante de los textos constitucionales y de las teorías de la ciencia política convencional (González, 2016, p. 29).

González se aparta de las visiones catastrofistas sobre el Estado colombiano tales como las del colapso parcial, el Estado fallido o la cooptación mafiosa del mismo. Sustenta que estas concepciones suponen al Estado como una obra ya concluida con la Constitución de 1886, o el fracaso en su conformación, o el poder de captura de los entes estatales por parte de narcotraficantes y paramilitares; mientras que las investigaciones de su equipo del caso colombiano y el estudio de los casos europeos, muestran que no hay una única forma de conformación del Estado, sino que obedece a las condiciones espacio-temporales de cada uno de ellos. Así pues, ni ha colapsado ni es fallido, simplemente está en un proceso de construcción que es preciso conocer más a fondo.

Propone una mirada más procesual de la formación del Estado en Colombia que permita entender las diferentes conexiones entre los órdenes local, regional y nacional en lo social, económico, cultural y político, además de dilucidar los nexos entre los aspectos estructurales y subjetivos de la vida social en diferentes momentos de su desarrollo.

Son aspectos estructurales: 1) La configuración social de las regiones, su poblamiento, cohesión y el problema agrario; 2) La integración territorial y política de las regiones y sus pobladores mediante el bipartidismo; y 3) Las tensiones y contradicciones de los dos anteriores, y la incapacidad del régimen político para tramitarlas adecuada y pacíficamente.

Los factores subjetivos serían las interpretaciones que personas y grupos sociales hacen de esas tensiones, sus (sic) valoración de las mismas tiene que ver con sus hábitos de pensamiento, sus preconcepciones y marcos ideológicos, que finalmente arrojan opciones y decisiones voluntarias frente a la situación así diagnosticada. (González, 2016, p. 27).

El miedo al pueblo, a la democracia, a la participación política de los sectores subalternos que se asimilan con anarquía o insurrección, han sido parte de dichos hábitos de pensamiento o el ethos de los grupos dominantes durante la época republicana y que heredaron del régimen colonial.

\section{Los miedos de los grupos subalternos y la defensa de sus derechos}

En los primeros años de la república los indígenas temían perder sus tierras (resguardos) y los afrodescendientes, no encontrar medios de vida que les garantizaran ejercer su libertad recién adquirida. Esto no significa que estos grupos hubieran sido actores pasivos durante el régimen colonial, al contrario, conocían y hacían uso de la legislación y del sistema judicial, estaban atentos a los cambios y a las diferencias entre las élites locales, y de estas con el gobierno monárquico de la metrópoli, para enfrentar sus miedos y defender sus derechos. La antropóloga e historiadora Marcela Echeverri encontró que: "indios y esclavos buscaron beneficiarse de las circunstancias politicas y dar forma a sus derechos a través de su constitución en aliados de los realistas" (Echeverri, 2009, p. 47).

Señala que entre 1808 y 1820 la comunidad indígena de Los Pastos se alió con Miguel Tacón, gobernador de la Provincia de Popayán, el capitán de las milicias de Barbacoas, Gregorio Angulo, y el Protector de Indios, Juan Díaz Gallardo, con quienes concertaron la condonación del tributo (abolido por la Constitución de Cádiz) a cambio de sus servicios como soldados en la defensa de Popayán; enfrentamientos que ganaron en dos oportunidades al Ejército de Quito.

Las autoridades españolas se aliaron con indígenas y esclavos pero, al tiempo, desconfiaban y les temian: "existía el precedente de rebeliones indígenas en el distrito de Pasto en 1781 y 1800 [...] como lo demuestra el temor de Tacón, la desconfianza del gobierno frente a los indios explica la desesperada necesidad de asegurar su colaboración con la causa real" (Echeverri, 2009, p. 50).

Estos temores también acompañaron a las autoridades de los grupos subalternos como lo ilustra Echeverri: los caciques rechazaron la condonación del tributo a los indígenas puesto que implicaba la pérdida de su poder, argumentaban que se estaba generando la discordia, división y rebelión entre sus pueblos.

Los grupos subalternos han tenido sus propios miedos: las comunidades indígenas a perder 
sus resguardos, los colonos a perder sus tierras y al consecuente descenso de sus condiciones de vida, y los afrodescendientes recién emancipados a volver a la esclavitud.

El historiador James Sanders en su estudio del Estado del Cauca durante la segunda mitad del siglo XIX, cuando en el país regía el modelo federal (1863 a 1885), se pregunta si los sectores subalternos sólo cumplieron un papel secundario enlistándose en las filas de los distintos sectores, sin entender los asuntos políticos que los enfrentaban.

Acude a las peticiones escritas de estos grupos a las autoridades y encuentra que los sectores subalternos participaron en las contiendas bipartidistas con sus propios objetivos sobre los cuales llegaron a acuerdos con las élites de los partidos: "emergieron tres distintas formas de republicanismo popular que he denominado liberalismo popular, conservatismo popular indigena, y republicanismo de los pequeños propietarios"3 (Sanders, 2004, p. 2).

Elprimeroloasocia conlos afro-colombianos recientemente liberados de la esclavitud y con los mestizos pobres, entre ellos, los artesanos; el segundo, con las comunidades indígenas y el tercero con los colonos migrantes del vecino Estado de Antioquia, cada uno con reivindicaciones propias que condujeron a significados distintos de los valores básicos del republicanismo: libertad, igualdad y fraternidad.

Para los colonos antioqueños la tierra era sinónimo de independencia y libertad; los indígenas se concentraron en proteger sus resguardos de los intentos de convertirlos en propiedad privada; a los afro-colombianos recién liberados, a los artesanos y a los mestizos pobres los unía la reivindicación de la igualdad de derechos en tanto ciudadanos que, a juicio de Sanders, para los afro-colombianos era aún más importante que la libertad, puesto que constituía la garantía de no retornar a la temida esclavitud.

Estos fines políticos son la sintesis de la visión del mundo y de la práctica vital de cada grupo. Para los afro-colombianos, quienes compartían con los artesanos y otros mestizos pobres el temor por su independencia económica, la reivindicación republicana de la igualdad de derechos en tanto ciudadanos era condición indispensable para garantizar que no retornarían a la esclavitud o a otras formas de dependencia y menosprecio personal.

Los afrodescendientes se organizaron en las llamadas Sociedades Democráticas en las que se encontraron con otros liberales populares, especialmente sectores medios de la población e incluso liberales de élite.

Sanders afirma que la igualdad simbolizaba varias cosas para los liberales populares: primero, junto con la libertad, la emancipación de la esclavitud; segundo, la garantía de los mismos derechos para pobres, afro-colombianos, ricos y blancos; tercero, la igualdad social con el fin de la deferencia debida a las clases poderosas; y por último, el fin de la dependencia económica.

La independencia económica se basaba en la tierra, así que los liberales afro-colombianos buscaron mostrar que el uso exclusivo de ésta con base en la propiedad privada no era un argumento liberal que guardara correspondencia con los nobles ideales de libertad, fraternidad e igualdad. Sostuvieron que no podría reclamarse la propiedad de la tierra hasta el punto de que los demás miembros de la comunidad se vieran privados de los medios de subsistencia, con lo cual estarían obligados a ser esclavos de los señores feudales y a vender implícitamente sus bienes personales e independencia, es decir, su conciencia y libertad, para ser peones y dejar de ser los ciudadanos de un pueblo libre.

El discurso liberal popular no se centró en la tenencia legal de tierras sino en los derechos al trabajo y a disfrutar de los frutos del mismo, a recolectar madera y otros productos de los bosques (resina) independientemente del título legal; también defendieron su derecho a producir $\mathrm{y}$ vender licor y otros productos declarados como monopolio del Estado o sobre los que pesaban gravosos impuestos.

Fundamentaron sus derechos ciudadanos en la sangre vertida por sus congéneres para defender las instituciones, el orden público, la independencia e integridad nacionales, es decir, los servicios prestados al Estado y al Partido Liberal. Recordaban que su contribución fue generosa dada su convicción en la causa republicana y en el Partido Liberal, diferenciándose así de algunos poderosos hacendados que habían adoptado la causa coaccionados por la fuerza de los acontecimientos.

Los liberales populares reivindicaron el derecho de las mujeres a la ciudadanía: "Las

3 Ésta y las siguientes traducciones son del autor del artículo. 
mujeres liberales populares tenían mucha más independencia que otras mujeres subalternas y, en consecuencia, participaron más abiertamente y con regularidad en la vida política del Cauca [...] una situación que se encuentra rara vez entre los indios y nunca entre los migrantes" (Sanders, 2004, p. 53).

Estos planteamientos de Sanders y de Echeverri permiten comprender que las comunidades indígenas y de afrodescendientes no han sido actores pasivos, que han enfrentado sus propios miedos y que los logros de finales del siglo XX son producto de sus acciones y aprendizajes en el largo plazo.

\section{Del miedo al terror: violencia politica y acciones de las victimas}

El miedo puede tramitarse dentro de los marcos institucionales con acuerdos, alianzas o los medios de coacción legítima, pero el terror implica desbordar las instituciones. La historia política colombiana muestra que el terror ha conducido a lo contrario de lo que con su uso se pretende: si se busca mantener el orden, constituye una motivación para subvertirlo; si se pretende substituirlo, conduce a afianzarlo.

El incumplimiento de las capitulaciones y las crueles sentencias a los líderes comuneros en 1872 fueron motivos para que Antonio Nariño adoptara la causa republicana y propugnara por la centralización del poder público, estaba convencido que, de ser derrotados, correrían la misma suerte de los comuneros. La reconquista española y su régimen del terror le darían la razón. En pueblos y ciudades colombianas se encuentran múltiples objetivaciones del terror: vestigios de los paredones de fusilamiento de centenares de mártires, placas conmemorativas con sus nombres, estatuas, monumentos y museos.

El rechazo al terror ibérico puede apreciarse en estas palabras de Constancio Franco Vargas en 1880:

La España no podrá justificar jamas, ni ante la moral, ni ante la civilizacion, ni ante el augusto tribunal de la historia, los horribles crímenes que sus tenientes cometieron en América.

El incendio, la flajelacion, la rapiña audaz i el patíbulo desvergonzado erijido por doquiera, fueron sus más sublimes hazañas [...]

Caldas fué uno de los primeros ciudadanos que proclamaron la independencia de América en
1810, consagrando a la causa de la libertad todos sus esfuerzos [...] hasta el mes de mayo del año del 16, en que perdida la batalla de la Cuchilla del Tambo, tuvo que ocultarse en la montaña de Paispamba, en donde fue apresado por los esbirros del pacificador Morillo [...]

Poco después se dirijió a Enrile pidiéndole se suspendiera la ejecución por unos pocos días miéntras rectificaba unos cálculos astronómicos, i aquel feroz tirano puso a continuación de la súplica del mártir estas palabras, que han hecho célebre su memoria: La España no necesita de sabios, está mandada a cumplir sin demora la sentencia. (Franco, 1880, pp. 68, 70, 72).

Aún sin acabar de diseñar las nuevas instituciones republicanas, el 27 de agosto de 1828 en Bogotá se atentó contra la vida de Simón Bolivar, salió ileso, sus autores fueron juzgados, algunos fusilados y otros, como Francisco de Paula Santander, enviados al exilio. Este hecho evidencia las dificultades de las élites para ponerse de acuerdo sobre el destino y la forma de gobierno de la nueva nación y de su permanente tentación de acudir a la fuerza para resolver las diferencias.

En la historia colombiana, al atentado personal se sumaron otras formas de violencia con las que, además de destruir personas y bienes, se busca generar terror. Uno de los momentos paradigmáticos es el conocido como La Violencia, que designa el enfrentamiento bipartidista de 1946 a 1958. Así lo consignó en 1959 el informe sobre la violencia en el Tolima de la Secretaría de Agricultura del departamento:

Actos de terror contra las personas y sus bienes, que concluyen inexorablemente en éxodo colectivo. Logrado este resultado, el paso siguiente es mantener latente el terror, para hacer desistir a las víctimas de presuntos o reales propósitos de reintegrarse a la propiedad abandonada [...]. No es explicable de otra manera el empeño sostenido, y aparentemente ilógico, de destruir casas e instalaciones (Grupo de Memoria Histórica, 2013, p. 113).

Tales actos de terror fueron perpetrados por grupos armados que:

Cometieron masacres, actos violentos con sevicia, crímenes sexuales, despojo de bienes y otros hechos violentos con los cuales "castigaban" al adversario. Rituales macabros, como el descuartizamiento 
de hombres vivos, las exhibiciones de cabezas cortadas y la dispersión de partes de cuerpos por los caminos rurales, que aún perviven en la memoria de la población colombiana (Grupo de Memoria Histórica, 2013, p. 112).

Estos grupos tenían nombres como coloradeños, tipacoques, chulavitas o pájaros, en los que se confundían el lugar de origen con la filiación política. Se habían formado desde los años treinta del siglo XX.

Al conquistar la presidencia de la República en 1930, finiquitando la hegemonía conservadora mantenida desde 1886, los liberales nombraron alcaldes de su partido incluso en poblaciones de reconocida mayoría conservadora, quedando al mando de:

Burocracias locales enemigas y poblaciones hostiles -incitadas a veces por sus curas párrocosoptaron por una respuesta típica de la historia colombiana: crear un aparato parainstitucional de policías cívicos para enfrentar el hecho de que su autoridad no fuese reconocida por la Policía municipal ni por la guardia departamental (González, 2016, p. 252).

Las relaciones de la Iglesia Católica con el Partido Conservador eran tan estrechas, que el historiador Gonzalo Sánchez se pregunta si las acciones de oposición al nuevo gobierno liberal consistian en "motines conservadores con apoyo eclesiástico o de levantamientos parroquiales con respaldo conservador" (González, 2016, p. 253).

González sostiene que haber puesto las instituciones locales y regionales al servicio de uno $\mathrm{u}$ otro partido o de intereses individuales, condujo a su creciente deslegitimación pero, reconoce que en esos primeros años del siglo XX se había logrado fortalecer el Estado hasta "no ser atacado por los jefes de la oposición en una guerra civil general, aunque no tan satisfactoriamente poderoso para evitar la violencia en algunas regiones y localidades" (González, 2016, p. 259).

La aparente solución de la violencia bipartidista del Frente Nacional en 1958 (la alternancia en la presidencia de cada partido durante los cuatro períodos siguientes y el reparto milimétrico de la burocracia entre ellos), dejó sin solucionar la situación de las guerrillas liberales y comunistas desconfiadas de las promesas de reinserción social y política, pues el referido reparto del poder excluía de facto las posibilidades de expresión, representación y participación política de otros partidos.

Algunos de estos liberales y comunistas organizados como autodefensas campesinas localizadas en Riochiquito (Cauca), Natagaima y Marquetalia (Tolima), El Pato (Caquetá) y Guayabero (Meta), después de la acción militar en su contra, decidieron conformar en 1964 las Fuerzas Armadas Revolucionarias de Colombia FARC-EP cuyos fundadores:

Fueron 48 campesinos que habitaban en la región de Marquetalia, una colonia agrícola fundada por ellos mismos diez años antes. Sus líderes principales fueron Manuel Marulanda Vélez y Jacobo Arenas, quienes encabezaron nuestra lucha hasta su muerte natural acaecida muchos años después (FARC-EP, 2016).

Como lo refiere González, el general Manuel José Bonnet, quien participó en dichos operativos militares cuando tenía el grado de subteniente, reconoció años después que "la principal consecuencia de la operación Marquetalia fue convertir "un movimiento sin peso político, muy localizado, en un fenómeno con un gran peso nacional e incluso internacional” (González, 2016, p. 354).

Las FARC-EP surgieron en el proceso de ampliación de la frontera agrícola en curso desde el siglo XIX y prolongaron "los conflictos agrarios de los años veinte y treinta en las zonas del Tequendama y Sumapaz donde habían surgido los primeros intentos de organización política y social al margen del bipartidismo” (González, 2016, p. 334).

Algunos historiadores consideran que una respuesta a la expansión territorial de las guerrillas fue la creación, hacia mediados de los años 70, de los grupos paramilitares en zonas de desarrollo productivo y de infraestructura:

Allí existían ya lazos de patronazgo y clientelas previamente constituidas, lo que hace coincidir la reacción frente a los abusos y extorsiones de la guerrilla con la desarticulación de los niveles de poder locales y regionales con relación tanto frente a la política del orden nacional como a la burocracia del Estado central (González, 2016, p. $387,388)$.

Un acercamiento a las magnitudes de estas formas de violencia se encuentra en el informe ¡Basta ya! del Centro de Memoria Histórica: 
220.000 personas murieron en hechos relacionados con el conflicto armado entre el 1 de enero de 1958 hasta el 31 de diciembre de 2012, de ellas el $81,5 \%$ eran civiles y el $18,5 \%$, combatientes; hasta el 31 de marzo del 2013: 25.007 desaparecidos, 1.754 víctimas de violencia sexual, 6.421 niños, niñas y adolescentes reclutados por grupos armados y 4.744 .046 personas desplazadas; 27.023 secuestros asociados con el conflicto armado entre 1970 y 2010; 10.189 víctimas de minas antipersonal entre 1982 y 2012 (Grupo de Memoria Histórica, 2013, p. 31, 32).

El Centro Nacional de Memoria Histórica estableció que todos los actores han acudido a todas estas formas de violencia, pero no en las mismas proporciones:

En términos de repertorios de violencia, los paramilitares ejecutaron en mayor medida masacres, asesinatos selectivos y desapariciones forzadas, e hicieron de la sevicia una práctica recurrente con el objeto de incrementar su potencial de intimidación. Las guerrillas, por su parte han recurrido primordialmente a los secuestros, los asesinatos selectivos, y los atentados terroristas, además del reclutamiento forzado y el ataque a bienes civiles. Con respecto a la violencia ilegal de miembros de la Fuerza Pública, se ha podido establecer con base en testimonios y en sentencias judiciales el empleo de modalidades como las detenciones arbitrarias, las torturas, los asesinatos selectivos y las desapariciones forzadas (Grupo de Memoria Histórica, 2013, p. 20).

Algunas de las víctimas de esta larga guerra han devenido en victimarios pero otras muchas han optado por otras acciones para poner fin a esta cadena de horrores

Rompiendo todos los cánones de los países en conflicto, la confrontación armada en este país discurre en paralelo con una creciente confrontación de memorias y reclamos públicos de justicia y reparación. La memoria se afincó en Colombia no como una experiencia del posconflicto, sino como factor explícito de denuncia y afirmación de diferencias. Es una respuesta militante a la cotidianidad de la guerra y al silencio que se quiso imponer sobre muchas víctimas. La memoria es una expresión de rebeldía frente a la violencia y la impunidad. Se ha convertido en un instrumento para asumir o confrontar el conflicto, o para ventilarlo en la escena pública (Grupo de Memoria Histórica, 2013, p. 13).

La galería de la memoria (Figura 3) es una de las formas como se reclama por las más de 60.630 personas desaparecidas desde 1970 hasta 2015, cifra que ha podido documentar el Centro Nacional de Memoria Histórica de Colombia 4 .

Las víctimas se han organizado de múltiples formas: el Comité de Solidaridad con los Presos Políticos, Asociación de Familiares de Detenidos Desaparecidos (ASFADES), Movimiento de Víctimas de Crímenes de Estado (MOVICE), Madres de Soacha (dedicada al esclarecimiento de los llamados "falsos positivos" es decir, el asesinato de jóvenes que luego eran presentados como guerrilleros muertos en combate) y País Libre (fundación que enfocó sus acciones contra el secuestro, funcionó de 1991 a 2017).

Las víctimas también jugaron un papel central en los diálogos del gobierno Santos con las FARC-EP. A La Habana asistieron 60 víctimas de todas las formas de violencia. Los negociadores insistieron que las víctimas eran el centro del proceso de negociación y que su compromiso era que no hubiera más víctimas y para ello lo primero era terminar el conflicto y garantizar su no repetición (Centro de Memoria, Paz y Reconciliación, 2015).

\section{Del miedo a la subjetivación de la esperanza}

Con base en lo hasta aquí expuesto, resulta comprensible la reacción de las víctimas y de los partidarios del Acuerdo final para la terminación del conflicto y la construcción de una paz estable y duradera ante los resultados del plebiscito del 2 de octubre de 2016: el miedo a que regresara la guerra, a que no se encontrara una salida a la situación generada, a que no fuera posible llegar a un nuevo acuerdo. Este miedo motivó varias acciones, algunas de las cuales se realizaron en la Plaza de Bolívar de Bogotá.

$4 \quad$ "Las galerías de memoria son formas de ocupación del espacio público mediante la instalación de distintos objetos e imágenes referidas a las víctimas, sus legados, sus ideas y sus proyectos. Las galerías son de construcción colectiva, cada participante aporta los elementos que selecciona para compartir con los observadores" (Centro Nacional de Memoria Histórica, 2016, p. 372). 


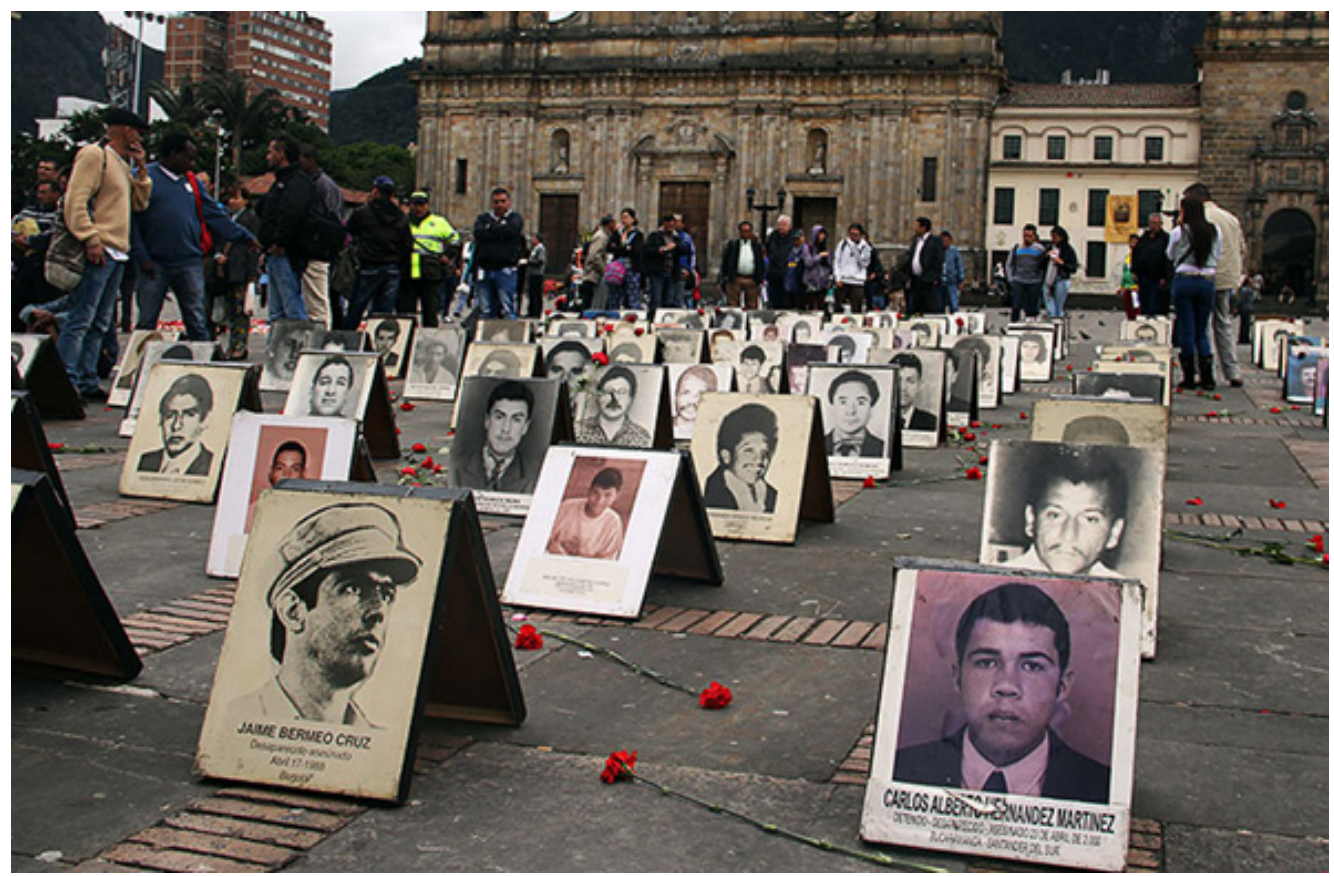

Figura 3. Galería de la memoria. Bogotá, 30 de agosto de 2011. Colprensa, 2014

Al atardecer del 2 de octubre, cuando en la Plaza de Bolivar estaban reunidos quienes apoyaron los acuerdos, con cada boletín de avance de los resultados iba creciendo el asombro, la decepción y la tristeza: el NO se impuso por un estrecho margen, 53.894 votos que representaron el $0.43 \%$ del total. La participación fue escasa, sólo 13.066.047 ciudadanos acudimos a las urnas (el $37,43 \%$ del potencial electoral), cerca de 3 millones menos que en las elecciones para presidente de la República realizadas dos años antes.

Algunos de los presentes en la plaza decidieron acampar alli hasta tanto se lograra superar el impasse con la firma de un nuevo acuerdo. Las manifestaciones y expresiones artísticas dieron forma a una parte del país que no se resignaba a retornar a la guerra, a otra decepción más.

Estudiantes de universidades públicas y privadas se unieron y convocaron para el 5 de octubre la que llamaron Marcha de las Antorchas (Figura 4), inspirados en la primera marcha de estas características liderada por Jorge Eliécer Gaitán en 1948, para protestar contra el gobierno conservador por la violencia que se ejercía hacia los integrantes del partido liberal. También recordaron la realizada en 1989 cuando miles de jóvenes universitarios marcharon en silencio contra la violencia, acontecimiento precursor del proceso que llevaría a la expedición de la nueva Constitución Política de 1991.

Hacia las cinco de la tarde, centenares de jóvenes se encontraban en el Planetario de Bogotá dispuestos a caminar por la carrera séptima, el mensaje era claro: "Independientemente si usted dijo sí, si usted dijo no, no importa, la paz es una sola y es de todos". Eran las siete de la noche y la Plaza estaba colmada de jóvenes, muchos vestidos de blanco, con banderas blancas y de Colombia, a la luz de las velas y las antorchas que portaban se podian leer carteles que decían: "Volver a la guerra jamás", "Hoy era el día 3 del desarme", "La paz es el camino, acuerdo ya"; también resonaron al unísono las voces: "No más guerra", "Ni un paso atrás, queremos la paz". Manifestaciones similares se vivieron en al menos 16 ciudades de Colombia (Gallo, 2016).

El 12 noviembre, con la firma del segundo Acuerdo, empezó a retornar la esperanza que se iba fortaleciendo con el acto protocolario del 24 de noviembre en el Teatro Colón de Bogotá, con la refrendación en el Congreso de la República el 29 y 30 de noviembre y con el pronunciamiento de la Corte Constitucional a favor del procedimiento rápido para que el Congreso expidiera las leyes necesarias para la implementación del Acuerdo.

El 29 de noviembre se realizó el concierto y acto ritual Acordes por la paz en el que participaron 


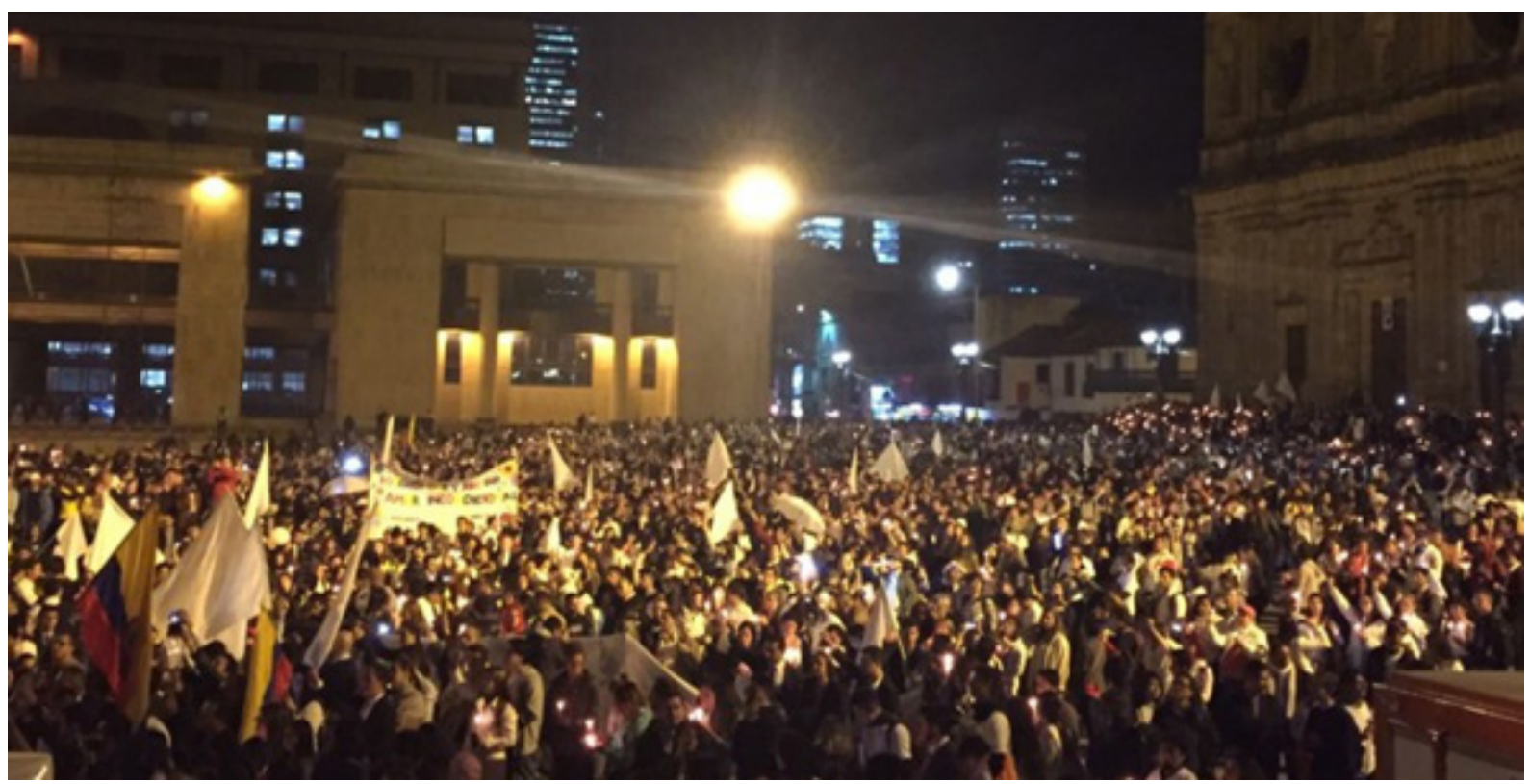

Figura 4. Marcha del silencio o de las antorchas. Bogotá, 5 de octubre de 2016. Fuente Gallo, 2016

autoridades indígenas, Alabaoras de Bojayá, Alabaoras de la Red de Mujeres del Pacífico Sur y Calle 13, entre otros; fue producido por la Dirección de Patrimonio Cultural de la Universidad Nacional de Colombia, el Centro Nacional de Memoria Histórica, la Agencia de Cooperación ACDI-VOCA (Usaid) y el Instituto Distrital de Artes (Idartes), entre otros (Rodríguez, 2016).

Pese al incumplimiento de algunos de los plazos, el acuerdo se ha ido implementando. En un corto tiempo se materializó la dejación de las armas por parte de las FARC-EP, que iniciaron así su proceso de constitución como partido político legal, todo lo cual representa un hito fundamental en la conformación del Estado-nación colombiano, de la esperanza en que es posible superar el miedo.

El punto de inflexión que representó el 20 de julio de 1810 en nuestro proceso de construcción de Estado-nación encuentra su complemento en el 23 de junio de $2016^{5}$ : el primer hito representó nuestra independización de los poderes coloniales externos, el segundo, de nuestras propias fuerzas centrífugas que hemos conocido con distintos nombres: patria boba, guerra de los supremos, violencia liberal conservadora, conflicto armado interno.

La superación de esta guerra civil con sus distintos nombres la expresó claramente el

$5 \quad$ Ese día se firmó el acuerdo sobre "Fin del conflicto: cese al fuego y de hostilidades bilateral y definitivo y dejación de las armas, garantías de seguridad". presidente Santos: se trata de que no sigamos matándonos los hijos de una misma nación. Y la forma jurídica de dicho nuevo orden social la expresó el ciudadano Timoleón Jiménez: se trata de reconocer en el Estado el monopolio legítimo de la fuerza, las armas y la tributación para de esta manera garantizar los derechos de todos los ciudadanos. Las dos partes también reconocieron el monopolio de la justicia: la Corte Constitucional decidiría las características del mecanismo de refrendación de los acuerdos de La Habana.

\section{Conclusiones}

Con base en lo hasta aquí expuesto es posible señalar que el miedo surge cuando se advierte un peligro inminente, para enfrentarlo se buscará evadirlo o protegerse. Para evadir el suceso o las condiciones que generan temor es posible: callar, olvidar, no querer recordar o mantenerse alerta; para protegerse: no demostrar miedo, ocultarlo o camuflarlo.

Al observar el Palacio de Justicia de Bogotá, en tanto objetivación del miedo, encontramos distintas formas de adecuar un edificio público para evadir el peligro: ocultar o enmascarar la edificación buscando que tome la forma de otra o aparentando las características de un edificio abierto al público, mientras que se interponen obstáculos a la 
libre circulación hasta lograr una construcción laberíntica; y, para protegerse: diseñar formas de desalojo distintas según los usuarios del edificio, seleccionar los materiales constructivos, hacer uso de tecnologías y equipos de seguridad tales como alarmas, cámaras y sensores.

El miedo al pueblo o a la democracia, a la participación política de los sectores subalternos, se ha institucionalizado con medidas que restringen derechos tales como el voto censatario o su negación a las mujeres, el uso reiterado de los recursos de excepción y la expedición de reformas que luego se incumplen; es decir, se han privilegiado los recursos de la dominación sobre los de la hegemonía.

El miedo a la participación política de los sectores subordinados se sustenta en la creencia de que ésta equivale al desorden, la anarquía o la insurrección, pero precisamente, las medidas tomadas para mantener el orden han llevado a lo contrario: a la violencia.

Miedos como el temor a la dilapidación de los precarios recursos públicos o la posible reacción de los españoles monárquicos, estaban en la base de las propuestas centralistas de Antonio Nariño que las concebía como forma para protegerse de estos peligros, mientras que haberlos subestimado y la consecuente incapacidad para tomar medidas de protección conjunta, facilitaron la reconquista española que devino en terror.

Los miedos de los grupos subalternos han sido: las comunidades indígenas a perder sus resguardos, los campesinos y colonos a perder sus tierras, los afrodescendientes recién emancipados a volver a la esclavitud, los campesinos y colonos insurrectos a ser asesinados, las víctimas y los partidarios del Acuerdo Final, a que la guerra retornara.

Para enfrentarestos miedos sehanorganizado e interpuesto demandas al Estado para que se garanticen sus derechos: las comunidades indígenas han restablecido sus formas de vida y de gobierno, han realizado acciones directas de recuperación de sus tierras, han creado organizaciones de carácter interétnico y han reclamado ante el Estado para su reconocimiento legal. Los afrodescendientes se organizaron en las Sociedades Democráticas junto con artesanos, otros grupos mestizos e incluso con las élites liberales, reivindicaron su derecho al trabajo y a disfrutar de sus productos por encima de los derechos de propiedad de las tierras (que no cuestionaban) o del monopolio estatal en determinados rubros de la economía; sustentaron que sus servicios a la patria $\mathrm{y}$ al partido liberal fundaban los reclamos sobre el ejercicio de sus derechos y sostenian que sobreponer el derecho de la propiedad privada sobre el acceso a los medios de subsistencia no se correspondía con los principios de una sociedad liberal: libertad, igualdad y fraternidad.

Los sectores subordinados han enfrentado sus miedos con la organización y las acciones para garantizar sus mínimas condiciones de vida y su reconocimiento como sujetos de derechos, como integrantes de la comunidad jurídico-política y partícipes de la comunidad nacional; mientras que los grupos dominantes han percibido estos reclamos y acciones como desorden, anarquía e insubordinación, temores que los han llevado a limitar los derechos y su puesta en práctica, todo lo cual ha obstaculizado la formación del sentimiento de pertenencia de los territorios del Estado-nación $\mathrm{y}$, en su lugar, ha dado paso al sentimiento de extrañamiento de dichos territorios.

Esta dificultad se ha acrecentado con el recurso del terror en el que han caído tanto los grupos dominantes, como algunos de los subordinados. Las cifras de las múltiples formas de violencia asociadas al conflicto armado interno así lo evidencian: atentados personales, masacres, desaparición y desplazamiento forzado de personas y comunidades, crímenes sexuales, descuartizamiento, destrucción de bienes, son formas que algunos han priorizado más que otros, pero que muestran la degradación de una guerra que algunos quieren mantener incluso después de haber llegado a un acuerdo para su desmonte.

El Acuerdo Final para la Terminación del Conflicto y la Construcción de una Paz Estable y Duradera suscrito entre el Gobierno Nacional y las FARC-EP constituyó un punto de inflexión en nuestro proceso de conformación del Estado-nación: la superación de la fragmentación territorial y del monopolio legítimo de la coacción, la justicia y la tributación. El estrecho margen de votos a favor del $\mathrm{NO}$ en el plebiscito del 2 de octubre de 2016 puso en vilo el Acuerdo Final, pero, el temor de retorno a la guerra, motivó el creciente involucramiento de la ciudadanía, su movilización y demanda al gobierno y a las FARC-EP para que encontraran una salida al impasse creado. Los avances en la implementación del Acuerdo representan la esperanza de que es posible superar el miedo y fortalecer el sentimiento de pertenencia de los territorios del Estado-nación colombiano. 


\section{Referencias}

Aristóteles. (2013). Arte poética - Arte retórica. México, D. F.: Editorial Porrúa S.A.

Cassirer, E. (1968). Antropología Filosófica. México: Fondo de Cultura Económica.

Centro de Memoria, Paz y Reconciliación (2015). Balance de 5 ciclos de visitas de delegaciones de víctimas a la mesa de diálogos de paz en La Habana:. Recuperado de: http://centromemoria. gov.co/balance-de-5-ciclos-de-visitas-dedelegaciones-de-victimas-la-mesa-de-dialogosde-paz-en-la-habana/

Centro Nacional de Memoria Histórica. (2016). Hasta encontrarlos. El drama de la desaparición forzada en Colombia. Bogotá, D. C.: CNMH. Recuperado de: http://www. centrodememoriahistorica.gov.co/micrositios/ hasta-encontrarlos/

Colprensa. (2014). Este año se han reportado 4539 personas como desaparecidas en Colombia. Consultado: agosto 2017. Recuperado de: http://www.elpais.com.co/judicial/esteano-se-han-reportado-4539-personas-comodesaparecidas-en-colombia.html

Echeverri, M. (2009). Los derechos de indios y esclavos realistas y la transformación política en Popayán, Nueva Granada (1808-1820). En: Revista de Indias, vol. LXIX, núm. 246 Págs. 45-72, ISSN: 0034-8341. Madrid: Consejo Superior de Investigaciones Científicas.

El Tiempo. (2015). Las 4 heridas abiertas de la tragedia del Palacio de Justicia. Recuperado de: http:// www.eltiempo.com/archivo/documento/CMS16417763

Valencia y Estupiñán, L. (2001). Ordenamiento territorial en Colombia. Perspectiva histórica y legal. Bogotá, D. C.: Universidad Libre.

FARC-EP. (2016). Quienes somos y porqué luchamos. Recuperado de: https://www.farc-ep.co/ nosotros.html

Franco, C. (1880). Rasgos biográficos de los próceres $i$ mártires de la independencia. Bogotá: Imprenta de Medardo Rivas. Recuperado de: http:// babel.banrepcultural.org/cdm/singleitem/ collection/p17054coll10/id/2336

Gallo, I. (5 de Octubre de 2016) En una multitudinaria marcha de silencio $y$ de velas encendidas los jóvenes piden paz. Las 2 Orillas. Recuperado de: http://www.las2orillas.co/ una-multitudinaria-marcha-silencio-velasencendidas-los-jovenes-piden-paz/
González, F. (2016). Poder y violencia en Colombia. Bogotá, D. C.: ODECOFI - CINEP

Grupo de Memoria Histórica. (2013). ¡Basta ya! Colombia: memorias de guerra y dignidad. Bogotá, D.C.: Centro Nacional de Memoria Histórica. Recuperado de: http://www. centrodememoriahistorica.gov.co/micrositios/ informeGeneral/

Habermas, Jürguen. (1998). Ciudadanía e identidad nacional. En: Habermas, Jürguen. Facticidad y validez. Madrid: Editorial Trotta S. A.

Habermas, J. (1999). Teoría de la acción comunicativa. 2 volúmenes. Madrid: Editorial Taurus.

Maya, T. (2007). Nuevo palacio de justicia de Bogotá. La arquitectura como máscara. En: Ensayos. Historia y teoría del arte. No. 13: 6 - 43. Diciembre de 2007. Recuperado de: http:// www.bdigital.unal.edu.co/44592/1/45835222439-1-SM.pdf

Monnet, J. (2013). El territorio reticular. En: Nates Cruz, Beatriz (coordinadora). Enfoques y métodos en estudios territoriales. Manizales: RETEC, Grupo de investigación territorialidades.

Nussbaum, M. (2006). El ocultamiento de lo humano. Repugnancia, vergüenza y ley. Buenos Aires: Katz Editores.

Rodríguez, S. (30 de noviembre del 2016). No más guerra, no más lágrimas, no más muertes. Revista Arcadia. Recuperado de: http:// www.revistaarcadia.com/musica/articulo/ concierto-acordes-por-la-paz-en-la-plaza-debolivar-bogota/60927

Sanders, J. (2004). Contentious republicans. Popular Politics, Race, and Class in Nineteenth-Century Colombia. USA: Duke University Press.

Valencia, H. (2010). Cartas de batalla: una crítica del constitucionalismo colombiano. Bogotá, D. C.: Panamericana Editorial.

Weber, M. (1997). Economía y sociedad. Bogotá, D. C.: Fondo de Cultura Económica.

Zambrano, C. (2013). Referentes construens. Memoria colectiva, actualización territorial y comunidad política, México y Colombia. San Agustín, Huila, Colombia. Ponencia presentada en el XII Seminario Internacional sobre Territorio y Cultura. Inédito 